\title{
Learning Communities as a New Way to Learn
}

\author{
M.C. Edelia Denisse Castañeda de la Cruz
}

Universidad Autonoma Chapingo

\begin{abstract}
A Learning Community (CA) for its acronym in Spanish, is an organized human community that builds and engages in its own educational and cultural project to educate itself, its children, its youth and its adults, within the framework of an endogenous, cooperative and supportive effort, based on a diagnosis not only of their hortcomings but, above all, of their strengths to overcome such weaknesses (Elboj et al., 2006). The only way to ensuring education for all and quality lifelong learning is to make education a necessity and a task for all, developing and synchronizing the resources and efforts of the local community in order to ensure more sustainable conditions. We are then, confronted with one of the most difficult and complex contemporary challenges: to think twice and to rebuild the bonds that the human develops, through society, in conjunction with the environment.
\end{abstract}

Keywords: Learning Communities as a New Way to Learn 